\title{
A familial case of Kikuchi-Fujimoto disease in dizygotic twins
}

\author{
Ashfaque Quadir ${ }^{1 *}$, Ken Peacock ${ }^{1}$, Peter Hsu², Davinder Singh-Grewal ${ }^{3}$ and Stephen Alexander ${ }^{4}$
}

\begin{abstract}
Background: Kikuchi-Fujimoto disease (KFD) or necrotizing histiocytic lymphadenitis, was described separately by both Kikuchi and Fujimoto in Japan in the early 1970's. Despite its rarity in the pediatric population, it is an important differential in persistent lymphadenopathy. Familial cases of KFD in the literature are rare. Here we describe the first reported case of KFD in non-identical twin sisters.

Case presentation: Twin 1 presented with a 3-week history of worsening right-sided cervical lymphadenopathy, daily fevers, significant lethargy, weight loss and arthralgia of her knees and ankles at the age of 12 years in 2015. She had had an unremarkable medical history. A biopsy of her lymph nodes showed histiocytic necrosis consistent with KFD. Twin 2 presented with a three-week history of lethargy, fatigue, weight loss and left-sided posterior cervical chain lymphadenopathy at 16 years of age in 2018. She had a history of frequently relapsing nephrotic syndrome and celiac disease. A biopsy of her lymph nodes was undertaken and showed histiocytic necrosis consistent with KFD.

Conclusions: KFD is a rare but self-limiting pathological process of necrotizing histiocytic lymphadenitis. Although further research is needed, there is an increasing amount of evidence which suggests a multifactorial pathological basis of disease. The two cases we document here are the first reported cases of familial KFD in dizygotic HLAidentical twins which reinforces the likely HLA-linkage in the etiology of KFD.
\end{abstract}

Keywords: Kikuchi-Fujimoto, Twins, Familial, Lymphadenopathy, Necrotizing, Histiocytic, Lymphadenitis

\section{Background}

Kikuchi-Fujimoto disease (KFD) or necrotizing histiocytic lymphadenitis, was described separately by both Kikuchi and Fujimoto in Japan in the early 1970's [1, 2]. Despite its rarity in the pediatric population, it is an important differential in persistent lymphadenopathy. KFD occurs predominantly in young women with associated symptoms of fever, lethargy, arthralgia and rash. Although the current etiology of KFD is unclear, associations have been made with autoimmune disease; with various infectious triggers including several viruses and other non-infective inflammatory conditions suggested.

\footnotetext{
*Correspondence: ashfaquequadir@gmail.com

'Department of General Medicine, The Children's Hospital at Westmead, Westmead, Sydney, NSW 2145, Australia

Full list of author information is available at the end of the article
}

Familial cases of KFD in the literature are rare. Here we describe the first reported case of KFD in non-identical twin sisters.

\section{Case presentation \\ Twin 1}

Twin 1 presented at the age of 12 years in 2015. She had had an unremarkable medical history although there was significant family history which is outlined in our second case. The family were of Lebanese descent. She presented with a 3-week history of worsening right-sided cervical lymphadenopathy, daily fevers, significant lethargy, weight loss and arthralgia of her knees and ankles. On examination, she had firm enlarged lymph nodes in the submandibular, posterior chain and supraclavicular regions predominantly on the right but also on the left

(c) The Author(s). 2020 Open Access This article is licensed under a Creative Commons Attribution 4.0 International License, which permits use, sharing, adaptation, distribution and reproduction in any medium or format, as long as you give appropriate credit to the original author(s) and the source, provide a link to the Creative Commons licence, and indicate if changes were made. The images or other third party material in this article are included in the article's Creative Commons licence, unless indicated otherwise in a credit line to the material. If material is not included in the article's Creative Commons licence and your intended use is not permitted by statutory regulation or exceeds the permitted use, you will need to obtain permission directly from the copyright holder. To view a copy of this licence, visit http://creativecommons.org/licenses/by/4.0/ The Creative Commons Public Domain Dedication waiver (http://creativecommons.org/publicdomain/zero/1.0/) applies to the data made available in this article, unless otherwise stated in a credit line to the data.
} 
Table 1 Investigation Results for Twin 1 and Twin 2

\begin{tabular}{|c|c|c|c|c|}
\hline \multicolumn{2}{|l|}{ Test } & \multirow{2}{*}{$\begin{array}{l}\text { Twin } 1 \\
106(L)\end{array}$} & \multirow{2}{*}{$\frac{\text { Twin } 2}{104(L)}$} & \multirow{2}{*}{$\begin{array}{l}\text { Normal Range } \\
115-150 \mathrm{~g} / \mathrm{L}\end{array}$} \\
\hline Full Blood Count & Haemoglobin & & & \\
\hline & White cell count & $3.4(\llcorner)$ & $3.6(L)$ & $4.5-13.5 \times 10^{\wedge} 9 / \mathrm{L}$ \\
\hline & Platelet count & 199 & 262 & $150-600 \times 10 \wedge 9 / L$ \\
\hline & Neutrophil count & 1.5 & 1.9 & $1.5-8.0 \times 10 \wedge 9 / L$ \\
\hline & Lymphocyte count & 1.5 & 1.4 & $1.0-4.0 \times 10 \wedge 9 / \mathrm{L}$ \\
\hline \multicolumn{2}{|l|}{ Liver Function Test } & Within normal limits & Within normal limits & \\
\hline \multicolumn{2}{|c|}{ Electrolytes/Urea/Creatinine } & Within normal limits & Within normal limits & \\
\hline \multicolumn{2}{|l|}{ C-reactive Protein } & $60(H)$ & $82.2(\mathrm{H})$ & $0-10 \mathrm{mg} / \mathrm{L}$ \\
\hline \multicolumn{2}{|c|}{ Erythrocyte Sedimentation Rate } & $101(H)$ & $50(\mathrm{H})$ & $0-20 \mathrm{~mm} / \mathrm{hr}$ \\
\hline \multicolumn{2}{|l|}{ ANA screen } & Negative & Negative & \\
\hline \multicolumn{2}{|l|}{ ENA screen } & Not detected & Not detected & \\
\hline \multicolumn{2}{|c|}{ Anti-dsDNA antibodies } & Negative & Negative & \\
\hline \multicolumn{2}{|l|}{ Complement C3 } & 1.68 & 1.43 & $0.75-1.75 \mathrm{~g} / \mathrm{L}$ \\
\hline \multicolumn{2}{|l|}{ Complement C4 } & 0.34 & 0.32 & $0.13-0.52 \mathrm{~g} / \mathrm{L}$ \\
\hline \multicolumn{2}{|l|}{ Urate } & 0.24 & 0.30 & $0.14-0.36 \mathrm{mmol} / \mathrm{L}$ \\
\hline \multicolumn{2}{|c|}{ Lactate Dehydrogenase } & 586 & $266(L)$ & $313-618 \mathrm{U} / \mathrm{L}$ \\
\hline \multirow[t]{4}{*}{ Immunoglobulins } & $\lg G$ & N/A & $4.33(L)$ & $6.24-14.40 \mathrm{~g} / \mathrm{L}$ \\
\hline & $\lg A$ & N/A & $<0.06(\mathrm{~L})$ & $0.59-3.96$ \\
\hline & $\lg M$ & N/A & 0.73 & $0.48-3.04$ \\
\hline & $\lg E$ & N/A & $<20$ & 0-200 IU/mL \\
\hline \multicolumn{2}{|c|}{ Toxoplasma serology } & IgM/lgG negative & lgM/lgG negative & \\
\hline \multicolumn{2}{|l|}{ EBV serology } & IgM/lgG negative & lgM/lgG negative & \\
\hline \multicolumn{2}{|c|}{ Other Infective serology } & Nil & $\begin{array}{l}\text { Mycoplasma lgM positive, RSV } \\
\text { PCR positive }\end{array}$ & \\
\hline \multicolumn{2}{|l|}{ Histopathology } & $\begin{array}{l}\text { Histiocytic necrosis, no bacteria } \\
\text { on gram stain, no AFB on ZN, } \\
\text { no fungal elements on PAS }\end{array}$ & $\begin{array}{l}\text { Histiocytic necrosis, no bacteria } \\
\text { on gram stain, no AFB on ZN, } \\
\text { no fungal elements on PAS, flow } \\
\text { cytometry showed no abnormal } \\
\text { cell population }\end{array}$ & \\
\hline \multicolumn{2}{|l|}{ Imaging } & $\begin{array}{l}\text { CT: Extensive cervical } \\
\text { lymphadenopathy with no } \\
\text { other focus }\end{array}$ & $\begin{array}{l}\text { Ultrasound: Multiple enlarged } \\
\text { lymph nodes in the left cervical } \\
\text { chain with increased vascularity, } \\
\text { largest measures } 20 \times 13 \mathrm{~mm}\end{array}$ & \\
\hline \multirow[t]{3}{*}{ HLA Class I } & A & 02:01, 03:02 & 02:01, 03:02 & \\
\hline & B & 08:01, 35:08 & 08:01, 35:08 & \\
\hline & C & 04:01, 07:02 & 04:01, 07:02 & \\
\hline \multirow[t]{5}{*}{ HLA Class II } & DRB1 & 03:01, 07:01 & 03:01, 07:01 & \\
\hline & DRB3 & 02:02 & 02:02 & \\
\hline & DRB4 & 01:03 & 01:03 & \\
\hline & DPB1 & 04:01, 23:01 & 04:01, 23:01 & \\
\hline & DQB1 & $02: 01,02: 02$ & $02: 01,02: 02$ & \\
\hline
\end{tabular}

side of her neck. There was no overlying erythema or cutaneous change noted. There was also no significant joint swelling or effusion.

She was initially treated with intravenous antibiotics with little improvement. A biopsy of her right sided lymph nodes was undertaken and showed histiocytic necrosis consistent with KFD. Her fevers resolved during her hospital admission although her lymphadenopathy persisted. A day prior to her discharge from hospital she developed an erythematous maculopapular rash over her face, back and limbs.

Over the following months, she developed alopecia areata, arthralgia and oral ulceration with persistent and 
severe fatigue. Her rash subsided without intervention. She was trialed on a short course of oral steroids and her symptoms slowly resolved. Twin 1 after 2 years of follow-up showed no serological evidence of Systemic Lupus Erythematosus or other autoimmune disease and was well and attending school.

\section{Twin 2}

The second twin presented at 16 years of age in 2018 . She had a history of frequently relapsing nephrotic syndrome from the age of 4 . She required treatment with corticosteroids until the age of 12 along with other immunosuppressive medications including Cyclosporin, Tacrolimus and Mycophenolate Mofetil. She was subsequently commenced on intermittent Rituximab infusions leading to remission and prior to presentation with her lymphadenopathy had been in remission for more than 2 years. Complications of her treatment included steroid-induced osteoporosis which required intermittent intravenous bisphosphonate therapy. She had also been diagnosed with celiac disease treated with a glutenfree diet and was noted to be a CYP2C19 intermediate metaboliser.

She presented with a three-week history of lethargy, fatigue, weight loss and left-sided posterior cervical chain lymphadenopathy. Fever commenced 2 days prior to her presentation with associated night sweats and a 2-day history of coryzal symptoms. On examination, she had extensive lymphadenopathy of her left posterior cervical chain with no rash, joint changes or hepatosplenomegaly.

She was initially commenced on intravenous antibiotics. Her serology was positive for Mycoplasma and her nasopharyngeal aspirate was PCR positive for Respiratory Syncitiovirus. A biopsy of her lymph nodes was undertaken and showed histiocytic necrosis consistent with KFD.
After a one-week admission, she was discharged when her fevers had resolved. She subsequently developed arthralgia and a rash similarly to her sister but had no serological evidence of SLE. She was commenced on a course of oral steroids with subsequent improvement in her symptoms over time.

\section{Investigations}

Both twins were comprehensively investigated with serological and biochemical testing as well as imaging, lymph node biopsy and tissue typing (Table 1 ). The twins were HLA identical on examination of 8 HLA loci. Histology from Twin 2's biopsy is shown in Figs. 1 and 2. They demonstrate loss of the lymph node's regular follicular architecture and areas of nonsuppurative necrosis. There is also a population of abnormal epithelioid cells which are positive for $\mathrm{T}$-cell and histiocyte markers and negative for B cell markers. These are proliferating blastic Tcells that are found in Kikuchi-Fujimoto disease.

\section{Discussion}

Kikuchi-Fujimoto disease remains more of a syndrome than a fully characterized disease. Twin 2 had nephrotic syndrome, a disease in which there is HLA linkage and evidence of viral activation similar to KFD [3]. The presence of mycoplasma with positive mycoplasma serology at the time of diagnosis in Twin 2 would be consistent with an infectious trigger for KFD [4].

Although very limited in number, there have been previous case reports documenting familial cases of KFD in siblings and even HLA-identical non-twin sisters [5-7]. Some of these familial cases have been documented in Japanese literature where related individuals who developed KFD were living in the same environment, were serologically positive for the same infectious trigger and had developed symptoms within a short time period of
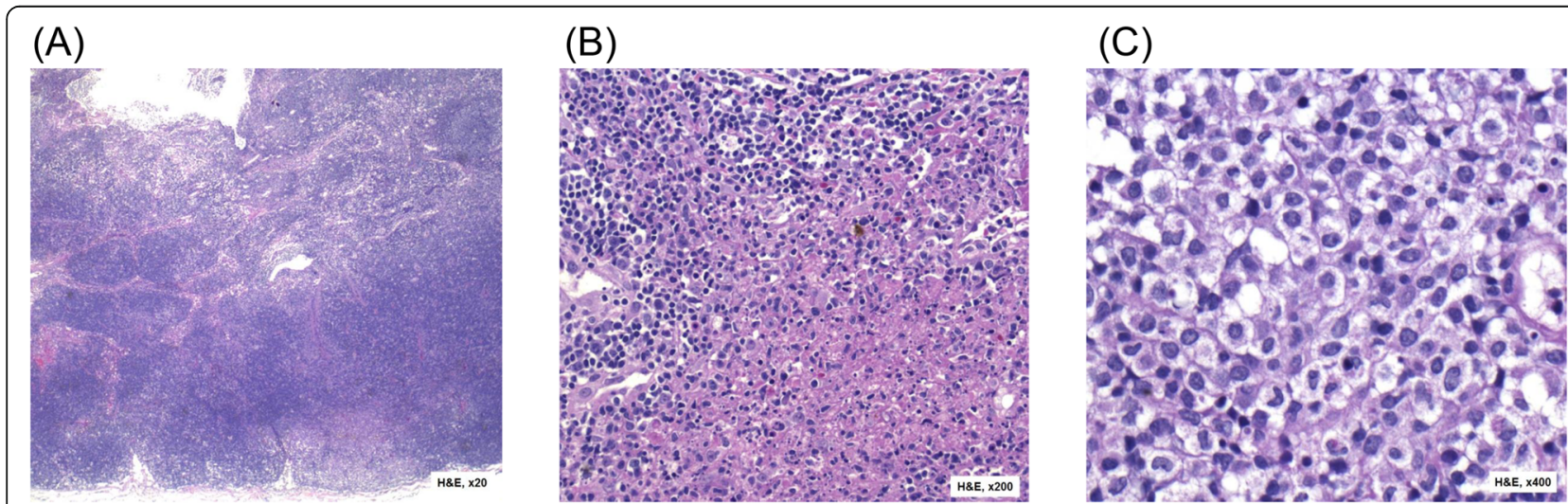

Fig. 1 Histopathology slides taken from a lymph node biopsy of Twin 2. Stained with Haematoxylin and Eosin with magnification as noted in the images. $\mathbf{a}$ - Loss of the normal follicular architecture of the lymph node with an area of abnormal cellularity in the subcapsular area. $\mathbf{b}$ - Abrupt coagulative necrosis with no neutrophils ("sterile" necrosis). c - Epithelioid cells with abnormal morphology which are the cells of origin for the coagulative necrosis 


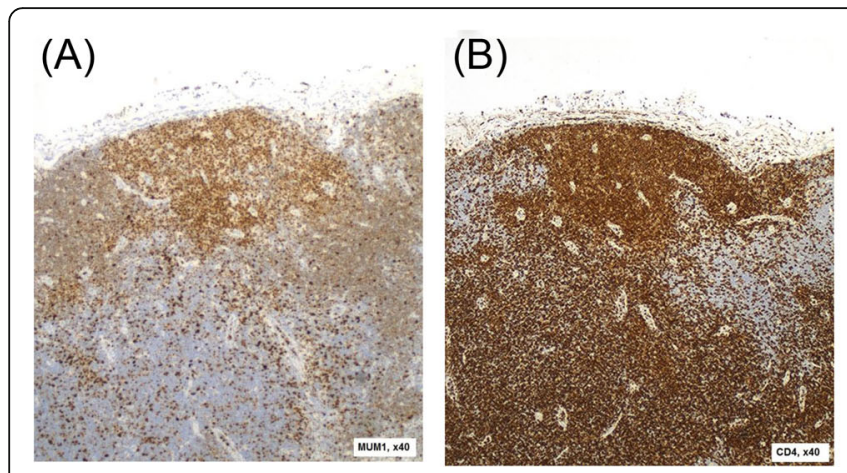

(C)

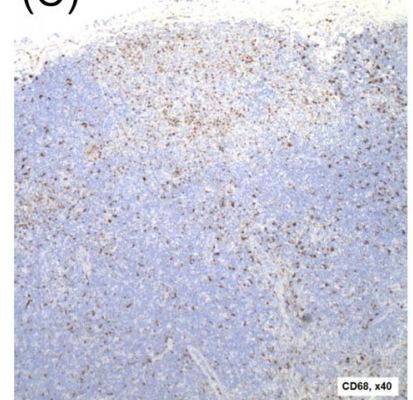

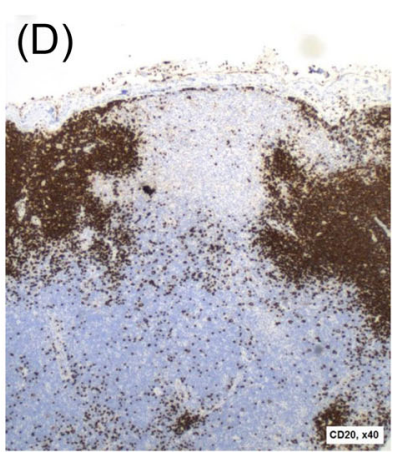

Fig. 2 Histopathology slides taken from a lymph node biopsy of Twin 2 with immunohistochemical staining for various cell surface markers. a Positive staining for MUM1 (general lymphocyte activation marker). b - Positive staining for CD4 (T-cell marker). c - Positive staining for CD68 (histiocyte marker). $\mathbf{d}$ - Negative staining for CD20 (B-cell marker). This shows the abnormal population of epithelioid cells which are positive for T-cell and hystiocyte markers and negative for B-cell markers and thus are the blastic T-cells that proliferate in Kikuchi-Fujimoto disease

each other. Exceptions to this include the case report by Amir et al. (2002) in Saudi Arabia where two sisters who were HLA-identical but not twins had presented 10 years apart with no obvious infectious trigger identified and the article by Stasiuk et al. (2011) which reported a similar case in two Aboriginal sisters from Northern Ontario $[5,6]$. The shared and common HLA for this disease suggests that like many other HLA-linked diseases, KFD is a two-step disease requiring a predisposing HLA and a secondary trigger such as an infection. Twin 2's background is particularly interesting as she has two other diseases that are linked to HLA Class II with celiac disease and nephrotic syndrome. This would be consistent with the paradigm that KFD needs an infectious trigger to develop but requires a specific HLA to develop disease. Although multiple offenders have been identified including Epstein Barr Virus, various Human Herpes Viruses, HIV, Torque Teno virus and Toxoplasma Gondii, it remains largely unclear if these pathogens are etiological or more likely inflammatory drivers of disease through TLR or other innate receptors $[4,8-10]$.

Of note, the HLA typing of the sets of siblings described in Stasiuk et al. and Amir et al.'s case reports are shown in Table $2[5,6]$. Interestingly, our twins' HLA-C type was identical to the siblings reported by Amir et al. ${ }^{6}$. Although the significance of this is unclear, this further supports the hypothesis regarding the etiology of KFD that we have put forward in this report.

There have been many associations with KFD and other diseases in various case reports in the literature including but not exclusive to hemolytic uremic syndrome, Hashimoto's thyroiditis, hemophagocytic lymphohistiocytosis

Table 2 Comparison of HLA-Typing in Siblings with Kikuchi-Fujimoto Disease

\begin{tabular}{|c|c|c|c|c|c|c|c|}
\hline & & Twin 1 & Twin 2 & Sibling 1 (Stasiuk et al) $)^{5}$ & Sibling 2 (Stasiuk et al) $)^{5}$ & $\begin{array}{l}\text { Sibling } 1 \\
\left(^{\text {Amir et al) }}\right.\end{array}$ & $\begin{array}{l}\text { Sibling } 2 \\
(\text { Amir et al) }\end{array}$ \\
\hline \multirow[t]{5}{*}{ HLA Class I } & A & 02:01, 03:02 & 02:01, 03:02 & 02 & 02,31 & 31 & 31 \\
\hline & $B$ & 08:01, 35:08 & 08:01, 35:08 & 39,35 & 39,51 & 35,49 & 35,49 \\
\hline & $C$ & 04:01, 07:02 & 04:01, 07:02 & & & 04,07 & 04,07 \\
\hline & BW & & & & & 04,06 & 04,06 \\
\hline & $C w$ & & & 07,04 & 07,15 & & \\
\hline \multirow[t]{9}{*}{ HLA Class II } & DRB1 & 03:01, 07:01 & 03:01, 07:01 & 08,14 & 08,14 & & \\
\hline & DRB3 & 02:02 & 02:02 & & & & \\
\hline & DRB4 & 01:03 & 01:03 & & & & \\
\hline & DPB1 & 04:01, 23:01 & 04:01, 23:01 & & & & \\
\hline & DR & & & & & 15,13 & 15,13 \\
\hline & DRW & & & & & 51,52 & 51,52 \\
\hline & $\mathrm{DQ}$ & & & & & 06 & 06 \\
\hline & DQA1 & 02:01, 05.01 & 02:01, 05.01 & & & & \\
\hline & DQB1 & $02: 01,02.02$ & $02: 01,02.02$ & 03 & 03,0402 & & \\
\hline
\end{tabular}


and more commonly, systemic lupus erythematosus [11-15]. Twin 2 had a background of nephrotic syndrome and celiac disease as discussed above. Both twins developed mucocutaneous symptoms that led to investigation for SLE but yielded no positive results. Although unclear, these associations with autoimmune conditions should guide clinicians when monitoring patients with prior KFD particularly in the context of disease surveillance or in the presence of new symptoms.

Interestingly, Twin 2 was serologically positive for Mycoplasma pneumoniae of which an association with KFD has not previously been documented. Although this could be coincidental, it should be noted that both Mycoplasma and KFD can lead to clinical signs and symptoms that may mimic other conditions or cause atypical presentations.

\section{Conclusion}

KFD is a rare but self-limiting pathological process of necrotizing histiocytic lymphadenitis. Although further research is needed, there is an increasing amount of evidence which suggests a multifactorial pathological basis of disease. The two cases we document here are the first reported cases of familial KFD in dizygotic HLAidentical twins which reinforces the likely HLA-linkage in the etiology of KFD. Due to its ability to mimic other more sinister illnesses, recognition and appropriate diagnosis of KFD is paramount to ensure that unnecessary investigations and treatment are avoided.

\section{Abbreviations}

KFD: Kikuchi-Fujimoto Disease; PCR: Polymerase Chain Reaction;

SLE: Systemic Lupus Erythematosus; HLA: Human Leukocyte Antigen;

HIV: Human Immunodeficiency Virus; TLR: Toll-like Receptors

\section{Acknowledgements}

The authors acknowledge the contributions of the Anatomical Pathology Department at the Children's Hospital at Westmead for their provision of histopathology slides and images and comments on their reports.

\section{Authors' contributions}

$A Q, K P$ and SA were major contributors in writing the manuscript. All authors read and approved the final manuscript.

\section{Funding}

Not applicable.

\section{Availability of data and materials}

Not applicable.

\section{Ethics approval and consent to participate}

Ethics approval was gained from the Sydney Children's Hospital Human Research Ethics Committee (\#CCR2018/29). Consent to participate was sought from the participant's parents using the consent form of the Sydney Children's Hospital Human Research Ethics Committee.

\section{Consent for publication}

Consent for publication was gained from the participants' parents using our local institutional consent form from our ethics committee.

\section{Competing interests}

The authors declare that they have no competing interests.

\section{Author details}

'Department of General Medicine, The Children's Hospital at Westmead, Westmead, Sydney, NSW 2145, Australia. ${ }^{2}$ Department of Immunology, The Children's Hospital at Westmead, Westmead, Sydney, NSW 2145, Australia. ${ }^{3}$ Department of Rheumatology, The Sydney Children's Hospitals Network, Westmead and Randwick, Sydney, NSW 2145, Australia. ${ }^{4}$ Department of Nephrology, The Children's Hospital at Westmead, Westmead, Sydney, NSW 2145, Australia.

Received: 12 May 2020 Accepted: 3 August 2020

Published online: 10 August 2020

References

1. Kikuchi M. Lymphadenitis showing focal hyperplasia with nuclear debris and phagocytes: a clinicopathological study. Acta Haematol Jpn. 1972;35:379.

2. Fujimoto Y. Cervical subacute necrotizing lymphadenitis. A new clinicopathological entity. Intern Med. 1972;20:920-7.

3. Gbadegesin RA, Adeyemo A, Webb NJ, Greenbaum LA, Abeyagunawardena A, Thalgahagoda S, et al. HLA-DQA1 and PLCG2 are candidate risk loci for childhood-onset steroid-sensitive nephrotic syndrome. J Am Soc Nephrol. 2015;26(7):1701-10.

4. Chiu C-F, Chow K-C, Lin T-Y, Tsai M-H, Shih C-M, Chen L-M. Virus infection in patients with histiocytic necrotizing lymphadenitis in Taiwan: detection of Epstein-Barr virus, type I human T-cell lymphotropic virus, and parvovirus B19. Am J Clin Pathol. 2000;113(6):774-81.

5. Stasiuk A, Teschke S, Williams GJ, Seftel MD. Kikuchi-Fujimoto disease: lymphadenopathy in siblings. CMAJ. 2011;183(1):E58-60.

6. Amir A, Amr S, Sheikh S. Kikuchi-Fujimoto's disease: report of familial occurrence in two human leucocyte antigen-identical non-twin sisters. J Intern Med. 2002;252(1):79-83.

7. Asano S, Akaike Y, Muramatsu T, Wakasa H, Yoshida H, Kondou R, et al. Necrotizing lymphadenitis: a clinicopathological and immunohistochemical study of four familial cases and five recurrent cases. Virchows Archiv A. 1991;418(3):215-23.

8. Stéphan JL, Jeannoël P, Chanoz J, Gentil-Perret A. Epstein-Barr virusassociated Kikuchi disease in two children. J Pediatr Hematol Oncol. 2001; 23(4):240-3

9. Huh J, Kang GH, Gong G, Kim SS, Ro JY, Kim CW. Kaposi's sarcomaassociated herpesvirus in Kikuchi's disease. Hum Pathol. 1998;29(10):1091-6.

10. Chong Y, Lee JY, Thakur N, Kang CS, Lee EJ. Strong association of torque Teno virus/torque Teno-like minivirus to Kikuchi-Fujimoto lymphadenitis (histiocytic necrotizing lymphadenitis) on quantitative analysis. Clin Rheumatol. 2019:1-7.

11. Khan ST, Naqvi R, Rashid R, Naqvi SA. A rare presentation of Kikuchi Disease with Hemolytic Uremic Syndrome. Pakistan Journal of Medical Sciences. 2019;35(2).

12. Lee EJ, Lee HS, Park JE, Hwang JS. Association Kikuchi disease with Hashimoto thyroiditis: a case report and literature review. Ann Pediatr Endocrinol Metab. 2018;23(2):99.

13. Chen J-S, Chang K-C, Cheng C-N, Tsai W-H, Su I-J. Childhood hemophagocytic syndrome associated with Kikuchi's disease. Haematologica. 2000;85(9):998-1000.

14. Santana A, Lessa B, Galrão L, Lima I, Santiago M. Kikuchi-Fujimoto's disease associated with systemic lupus erythematosus: case report and review of the literature. Clin Rheumatol. 2005;24(1):60-3.

15. Quintas-Cardama A, Fraga M, Cozzi S, Caparrini A, Maceiras F, Forteza J. Fatal Kikuchi-Fujimoto disease: the lupus connection. Ann Hematol. 2003;82(3): 186-8.

\section{Publisher's Note}

Springer Nature remains neutral with regard to jurisdictional claims in published maps and institutional affiliations. 